\title{
Associação de procedimentos para a resolução estética de dente com alteração de cor e tratado endodonticamente
}

\author{
- João Felipe Besegato Departamento de Odontologia Restauradora, Faculdade de Odontologia de Araraquara, Universidade \\ Estadual Paulista (Unesp), Araraquara, SP, Brasil • Isabela Alves Matioli Departamento de Odontologia Restauradora, \\ Universidade Estadual de Londrina (UEL), Londrina, PR, Brasil • Adrieli Burey Universidade Estadual de Ponta Grossa \\ (UEPG), Ponta Grossa, PR, Brasil • Daniel Poletto Universidade Paranaense (Unipar), Francisco Beltrão, PR, Brasil • Adriana \\ de Oliveira Silva Departamento de Odontologia Restauradora, Universidade Estadual de Londrina (UEL), Londrina, PR, \\ Brasil - Márcio Grama Hoeppner Departamento de Odontologia Restauradora, Universidade Estadual de Londrina (UEL), \\ Londrina, PR, Brasil
}

RESUMO || Objetivo: Relatar e discutir o tratamento realizado para solucionar o problema estético decorrente da alteração cromática do incisivo central superior esquerdo (21), tratado endodonticamente e com restauração insatisfatória de resina composta. Relato do caso: Agentes clareadores à base de perborato de sódio e/ou peróxido de hidrogênio foram utilizados em técnicas intra e extracoronária, imediata e mediata. Após as sessões de clareamento dentário, o resultado obtido não foi satisfatório frente aos anseios do paciente, fato que justificou a substituição da restauração em resina composta com recobrimento da face vestibular (faceta direta). Conclusão: Considerando os resultados clínicos obtidos, pôde-se concluir que o clareamento dentário, embora conservador às estruturas dentárias, não foi efetivo à resolução do problema decorrente da alteração cromática. Por sua vez, o desgaste da face vestibular e posterior restauração direta com resina composta, embora menos conservador, foi satisfatório para solucionar o problema estético e se mostra efetivo após dois anos de controle clínico.

DESCRITORES || Estética Dentária; Clareamento Dental; Resinas Compostas.

ABSTRACT | Procedure associations' for esthetic resolution of discolored and endodontically treated tooth - Objective: The aim of this study was to present the clinical treatment performed in order to solve an aesthetic problem resulting from a color change of the upper central incisor (21) endodontically treated and with an unsatisfactory composite resin restoration. Case description: After anamnesis, clinical and radiographic examination was performed the dental bleaching of the tooth 21. The bleaching agents (sodium perborate and/ or hydrogen peroxide) were used in different application techniques: intracoronal and external; "waking bleach" and "in-office" bleaching. For the indication and treatment's prognosis were considered: quantity and quality of the dental tissue, quality of endodontic treatment and time of chromatic alteration reported by the patient. After the bleaching sessions, the result obtained was not satisfactory in front of the patient's wishes. Thus, a direct composite resin restoration was performed. Conclusion: Considering the clinical outcomes achieved it can be concluded that the dental bleaching, although conservative to the dental structures, was not effective in order to solve the color change. Besides, direct composite resin restoration, although less conservative, was satisfactory to solve the aesthetic problem and it has been effective after two years of follow-up.

DESCRIPTORS | Esthetics Dental; Tooth Bleaching; Composite Resins.

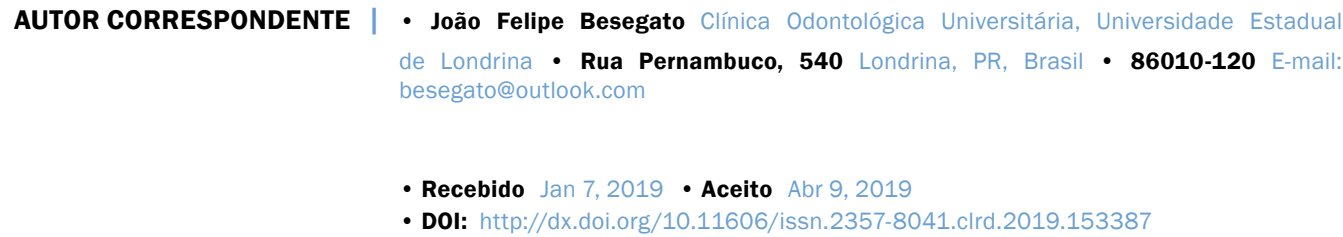




\section{INTRODUÇÃO}

O sorriso é fundamental nas relações sociais e por isso é crescente o número de pacientes que buscam tratamento odontológico, não somente para promoção da saúde, mas também por necessidade estética. Dentre as principais queixas está o descontentamento com a cor dos dentes, ${ }^{1}$ problema para o qual se indica o clareamento dentário com produtos oxidantes à base de peróxido de hidrogênio, que, por ser um tratamento conservador, de resultados rápidos e baixo custo, tornou-se popular. ${ }^{2}$

O peróxido de hidrogênio utilizado, que se degrada em oxigênio termicamente instável derivado de um radical livre, ${ }^{3}$ tem poder oxidativo e capacidade de degradar moléculas orgânicas complexas, responsáveis pela alteração cromática dos dentes. 4

Em dentes tratados endodonticamente, a aplicação de peróxido de hidrogênio no interior da câmara pulpar é uma proposta de tratamento estético de fácil execução e mais conservadora aos tecidos dentários, quando comparado aos procedimentos restauradores. ${ }^{5,6}$ Entretanto, o prognóstico é imprevisível. 7 Assim, frente à alteração cromática acentuada, em benefício da estética não está descartada a opção por tratamentos mais invasivos, seja com facetas diretas, em resina composta, seja com indiretas, em resina composta ou cerâmicas. ${ }^{8}$

Considerando o exposto, o objetivo deste trabalho é relatar e discutir o resultado obtido por meio de tratamento estético realizado para a melhora da condição clínica do incisivo central superior esquerdo (dente 21), tratado endodonticamente.

\section{RELATO DE CASO CLÍNICO}

Paciente do gênero feminino, 33 anos, compareceu a Clínica Odontológica Universitária da Universidade Estadual de Londrina (COU/UEL) tendo como queixa principal a alteração cromática no incisivo central superior esquerdo (21). Anamnese, exame clínico intrabucal e exame radiográfico permitiram diagnosticar alteração cromática, restauração em resina composta insatisfatória e tratamento endodôntico satisfatório no dente 21 (Figura 1: A e B). Questionada, a paciente relatou traumatismo do dente 21, há 15 anos e, em consequência, realização do tratamento endodôntico e restaurador. Também relatou alteração cromática do dente 21, perceptível após o traumatismo e tratamento endodôntico. Por esse motivo, informou que já se submetera a

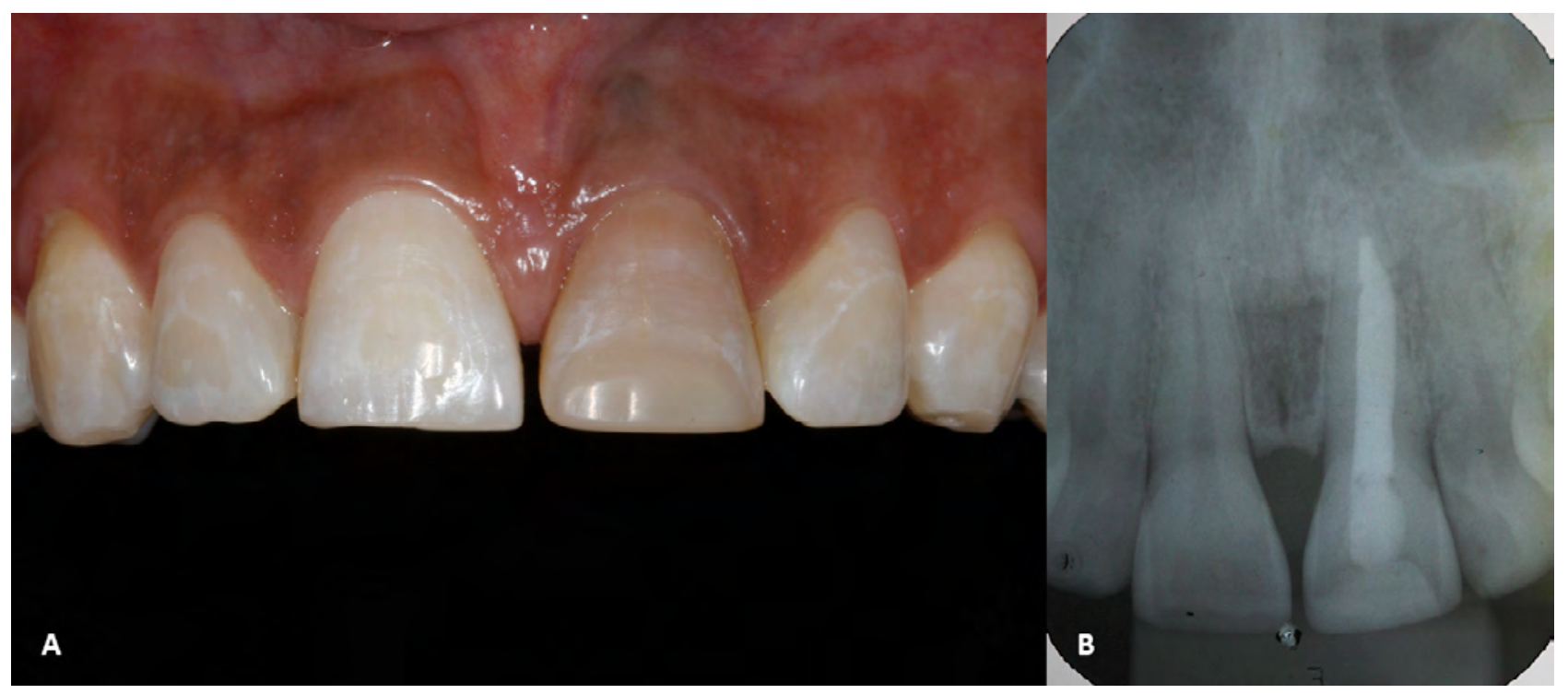

FIGURA 1 | A: visão clínica inicial, B: visão radiográfica inicial. 
tratamento estético de clareamento dentário, com sucesso imediato, mas não a longo prazo.

Considerando a avaliação da quantidade e qualidade do remanescente dentário, da qualidade do tratamento endodôntico, do grau e do tempo de alteração cromática relatada, foi proposto, em atenção à queixa principal da paciente: $1^{0}$ ) clareamento dentário, por meio da associação de técnicas (de acordo com o local de aplicação do agente clareador: técnica interna/intracoronária e técnica externa/extracoronária, e de acordo com o tempo de ação do agente clareador: técnica imediata e técnica mediata) e de agentes clareadores (perborato de sódio associado a peróxido de hidrogênio, e somente peróxido de hidrogênio), em diferentes concentrações; e $2^{\circ}$ ) substituição da restauração em resina composta clinicamente insatisfatória. $\mathrm{Na}$ oportunidade, a paciente foi comunicada dos riscos e limitações do clareamento e quanto à possibilidade de o tratamento não corresponder a suas expectativas. Por esse motivo, podendo haver a necessidade do recobrimento vestibular com material restaurador.

Após ciência e concordância da paciente, foi realizada a tomada de cor dos dentes, com base na escala Vita Clássica (Vita Lumin, Vita Zahnfabrik, Bad Sackingen, Alemanha). O dente 21 apresentou cor $\mathrm{C}_{4}$ (Figura 2: A); os dentes 11, 31 e 41 cor A2, e os dentes 13, 23, 33 e 43, cor B3. Todas as etapas do tratamento foram fotografadas com câmera digital (Canon EOS Rebel T3i, Canon, Tóquio,
Japão) para auxiliar na comparação entre o pré e o pós-tratamento.

O dente 21 foi preparado para receber o agente clareador primeiramente na técnica intracoronária mediata. Para tanto, com ponta diamantada esférica (\#1013, Kg Sorensen, Cotia, SP, Brasil), montada em alta rotação, sob refrigeração, foi realizada abertura palatina para limpeza da câmara pulpar e acesso ao conduto radicular. Exposta a abertura cervical do canal radicular e tendo como referência a margem gengival coronária vestibular do dente a ser clareado, $3 \mathrm{~mm}$ do material obturador do terço cervical radicular foi removido com broca Largo (\#2, Dentsply Maillefer, Tulsa, Oklahoma, USA), montada em baixa rotação.

Na sequência, sobre o material obturador radicular remanescente foi confeccionado um plug cervical (rolha ou tampão cervical) com material restaurador provisório (Coltosol, Vigodent, Rio de Janeiro, RJ, Brasil) de $2 \mathrm{~mm}$ de espessura, aproximadamente. No interior da câmara pulpar foi inserido algodão umedecido e a abertura palatina selada com o mesmo material restaurador provisório utilizado para a confecção do plug cervical.

Passados sete dias, sob isolamento absoluto do campo operatório, foi preparada e inserida no interior da câmara pulpar pasta clareadora obtida a partir da mistura do perborato de sódio e peróxido de hidrogênio a 20\% (Whiteness Perborato, FGM Produtos Odontológicos, Joinville, SC, Brasil),

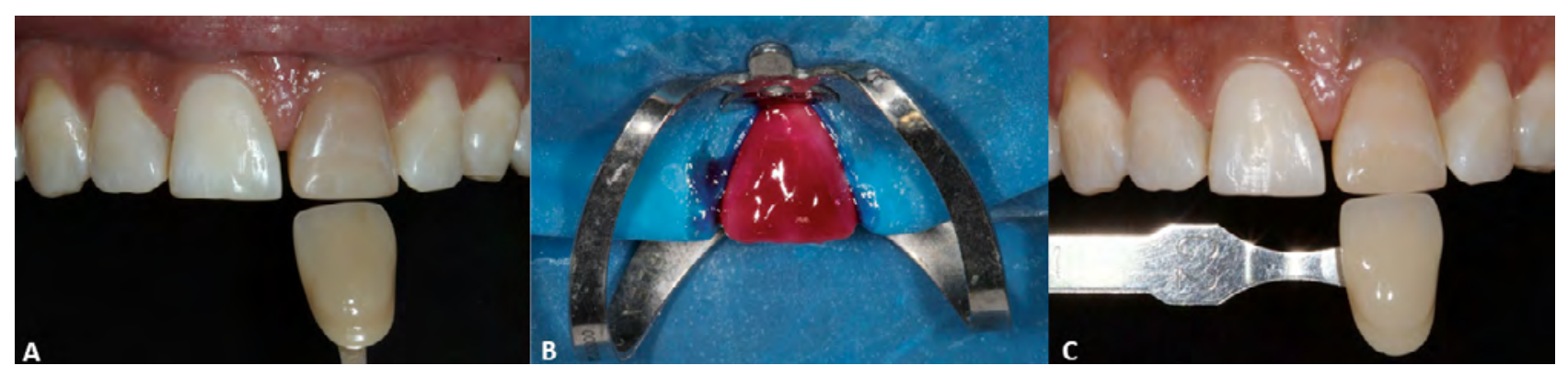

FIGURA 2 || A: análise inicial da cor do dente 21 (C4), B: aplicação do agente clareador com a técnica extracoronária, C: análise da cor do dente 21 após as sessões de clareamento (C2). 
de acordo com as recomendações do fabricante. A câmara pulpar foi selada com o material restaurador provisório utilizado na sessão anterior.

A cada sete dias, a pasta clareadora foi trocada. Assim, foram duas trocas a partir da primeira sessão de clareamento, perfazendo três sessões de clareamento em 21 dias de ação do agente clareador na técnica intracoronária. A partir de então, o dente passou a ser clareado pela técnica intra e extracoronária imediata, com peróxido de hidrogênio a 35\% (Whiteness HP, FGM Produtos Odontológicos, Joinville, SC, Brasil), aplicado sob isolamento absoluto do campo operatório e de acordo com as recomendações do fabricante (Figura 2: B). Foram duas sessões de clareamento, com intervalo de sete dias. Ao término de cada sessão de clareamento com peróxido de hidrogênio a 35\%, pasta de hidróxido de cálcio (hidróxido de cálcio PA + soro fisiológico) foi inserida e selada no interior da câmara pulpar, com material restaurador provisório (Coltosol, Vigodent, Rio de Janeiro, RJ, Brasil). Duas semanas após a última sessão de clareamento, foi avaliada alteração cromática do dente 21 de $\mathrm{C}_{4}$ para $\mathrm{C} 2$, de acordo com a escala Vitta Clássica (Figura 2: C).

Assim, considerando que o tratamento clareador não foi capaz de propiciar alteração de cor satisfatória à paciente, foi proposto tratamento mais invasivo, ou seja: recobrimento estético da face vestibular. Foi apresentada a opção pelo procedimento direto, com resina composta, ou indireto, com material cerâmico, tendo a paciente optado pela faceta em resina composta.

Para a remoção da restauração em resina composta insatisfatória e preparo da face vestibular do dente 21, foram utilizadas pontas diamantadas da primeira e segunda série (\#2135 e \#2135F, Kg Sorensen, Cotia, SP, Brasil), sob isolamento absoluto modificado do campo operatório (lençol de borracha seccionado do dente 13 ao 23 e mantido aderido a mucosa vestibular e lingual com auxílio de adesivo à base de cianoacrilato) (Figura 3: A).

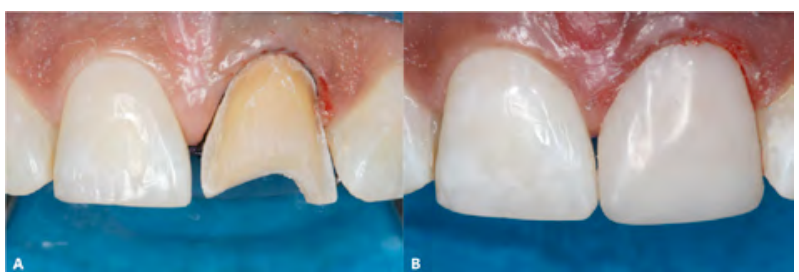

FIGURA 3 | A: preparo do dente 21 para facetamento estético com resina composta, B: resultado sete dias após a realização da faceta direta em resina composta.

Finalizado o preparo, esmalte e dentina das faces vestibular e palatina, e dentina da câmara pulpar coronária foram condicionados com ácido fosfórico a 35\% (Ultra Etch ${ }^{\circledR}$, Ultradent Products Inc., South Jordan, UT, USA), lavados com água e secos para posterior aplicação do sistema adesivo (Adper ${ }^{\mathrm{TM}}$ Single Bond 2, 3M ESPE, St. Paul, MN, USA). Este foi fotopolimerizado com aparelho fotopolimerizador à base de LED (Light Emitting Diode) (Emitter A FIT, Schuster, Santa Maria, RS, Brasil), com potência de $1250 \mathrm{mw} / \mathrm{cm}^{2}$, durante 20 segundos em cada face.

A câmara pulpar foi restaurada com resina composta nanoparticulada (Filtek Z350 ${ }^{\mathrm{TM}} \mathrm{XT}$, 3M ESPE, St. Paul, MN, USA) na cor WXB. A face vestibular foi restaurada com resina micro-híbrida (Amelogen ${ }^{\circledR}$ Plus, Ultradent Products Inc., South Jordan, UT, USA), em diferentes graus de opacidade e cor, sendo: primeiro incremento cor OW; segundo incremento cor A2 no terço cervical; terceiro incremento cor A1 nos terços médio e incisal; e quarto incremento, sobre toda a face vestibular, cor EN. O acabamento imediato da face vestibular foi realizado com discos de lixa Diamond Master (FGM Produtos Odontológicos, Joinville - SC - Brasil), ponta diamantada \#3195 F (KG Sorensen Ind. \& Com., Alphaville, SP, Brasil) e broca multilaminada \#9714 FG (Microdont, São Paulo, SP, Brasil); da face lingual com ponta diamantada \#3168 F (KG Sorensen Ind. \& Com., Alphaville, SP, Brasil) e broca multilaminada \#9406 FG (Microdont, São Paulo, SP, Brasil), e da face proximal com lamina de bisturi número 12 (Feather Safety Razor, Osaka, Japan) e tiras de lixa Epitex (GC America Inc., Chicago, IL, USA). 
Após sete dias, em resposta à solicitação da paciente, foi realizado o fechamento do diastema entre os dentes 11 e 21 com a resina composta micro-híbrida (Amelogen ${ }^{\circledR}$ Plus, Ultradent Products Inc., South Jordan, UT, USA), nas mesmas cores da restauração inicial. Após o acabamento com os instrumentais cortantes manuais e rotatórios, o polimento da restauração foi realizado com sequencial de taças e escova Jiffy ${ }^{\circledR}$ (Ultradent Products, Inc., South Jordan, UT, USA) (Figura 3: B).

Após 12 e 24 meses de proservação clínica e radiográfica, foi verificada a manutenção do resultado obtido pelo tratamento (Figura 4: A, B, C e D e Figura 5).

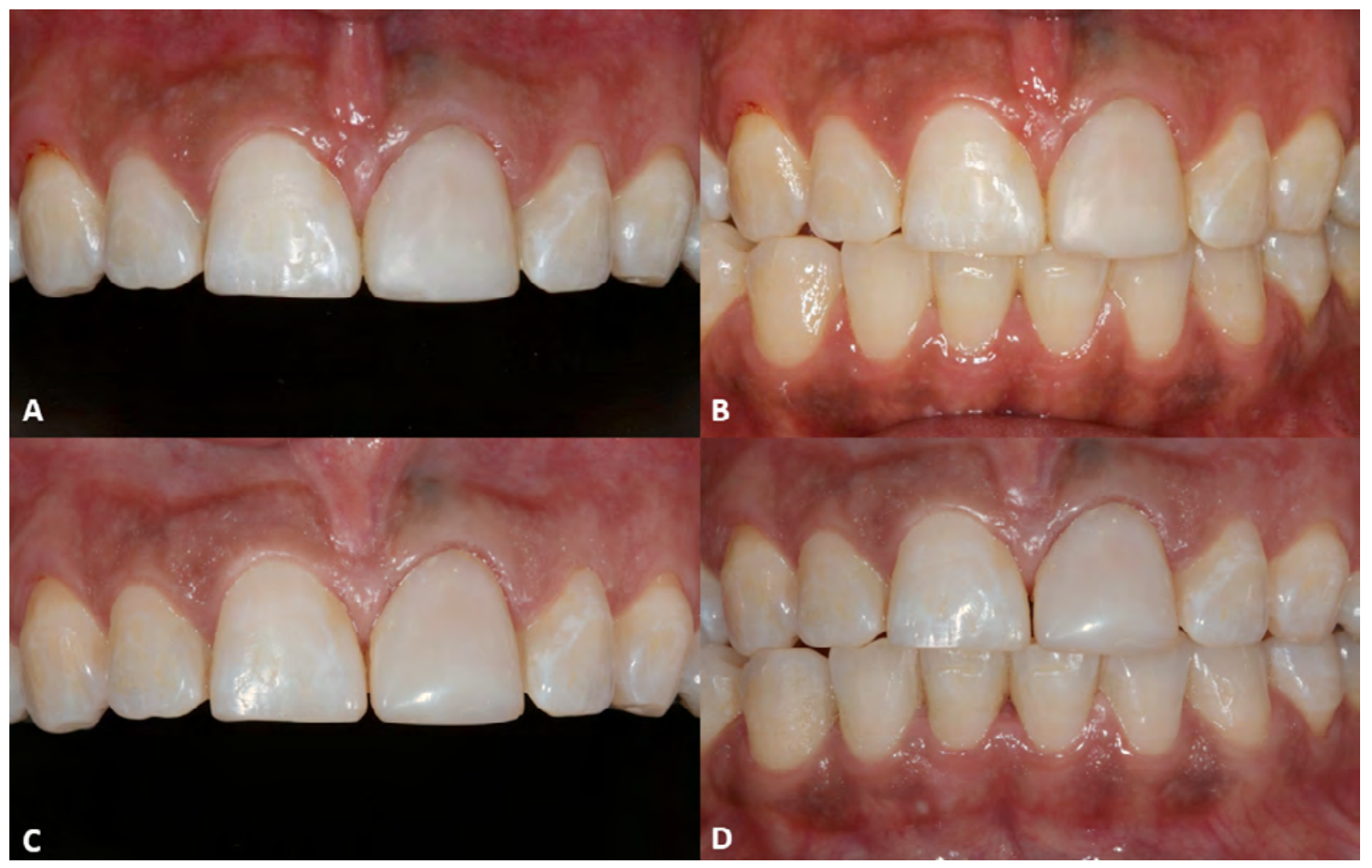

Figura 4 | A e B: condição clínica após 12 meses de proservação, C e D: condição clínica após 24 meses de proservação.

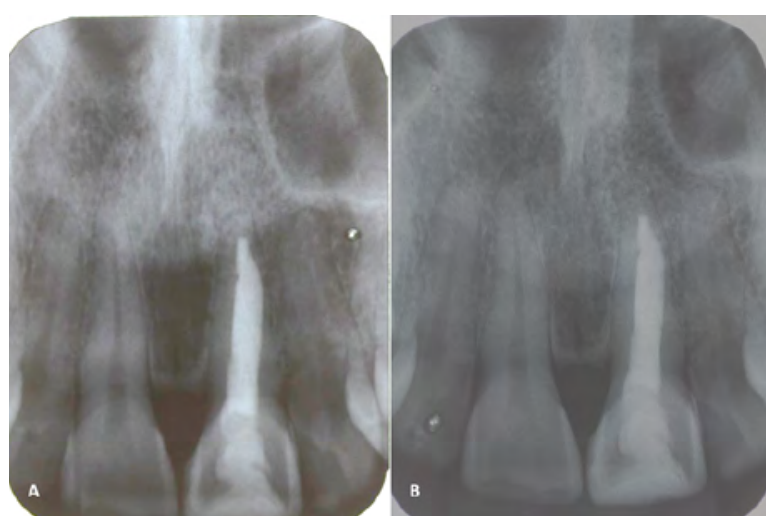

Figura 5 || A: condição radiográfica após 12 meses de proservação, B: condição radiográfica após 24 meses de proservação.

\section{DISCUSSÃO}

O planejamento e a escolha do tratamento foram norteados pelos seguintes fatores: 1) informações obtidas na anamnese referentes ao tempo de escurecimento do dente 21 e tratamento clareador já realizado, mas sem sucesso a longo prazo; 2) informações clínicas e radiográficas referentes à qualidade e à quantidade de remanescente dentário, à qualidade do tratamento endodôntico e às condições periapicais.

Para reverter ou minimizar a diferença de cor diagnosticada no dente 21, queixa principal da 
paciente, a utilização de agentes oxidantes foi a primeira opção de tratamento. O clareamento, quando corretamente indicado, é um procedimento conservador às estruturas dentárias, de baixo custo em relação aos tratamentos restauradores e com resultado favorável. ${ }^{6}$

Para tanto, foi realizada abertura e limpeza da câmara pulpar e, na sequência, confecção do plug cervical (selamento cervical), com o propósito de limitar a área de ação do agente clareador à dentina coronária e evitar a reabsorção radicular externa, efeito adverso do clareamento interno., ${ }^{9,10}$ A literatura correlata é inconclusiva quanto ao material mais adequado para a confecção do plug cervical, mas sua efetividade está relacionada à espessura, que deve ser de $1 \mathrm{~mm}$, no mínimo. ${ }^{10}$ No caso relatado, facilidade de aplicação, estética aceitável, atividade antimicrobiana e selamento marginal foram as propriedades consideradas para a escolha de um selador temporário à base de óxido de zinco. ${ }^{11,12}$

A reabsorção radicular externa pós-clareamento interno, hipoteticamente, pode ser decorrente da difusão do peróxido de hidrogênio até o periodonto cervical, do potencial hidrogeniônico $(\mathrm{pH})$ ácido do agente clareador, da anatomia dentária cervical, do histórico de traumatismo dentário, da utilização do calor para potencializar a ação do agente clareador e/ou da presença de processo inflamatório na região cervical. ${ }^{13-18}$ Independentemente da etiologia, o controle radiográfico sistemático é relevante para o diagnóstico precoce da reabsorção radicular externa. No presente relato, passados 24 meses do clareamento intracoronário, não foi diagnosticada imagem sugestiva da perda de tecido duro na região cérvico-radicular (Figura 5). Vale ressaltar que, findado o tratamento, a paciente foi orientada e motivada quanto à importância do controle clínico e radiográfico anual e, percebido qualquer sinal clínico, como sangramento gengival e/ou sensibilidade, procurar imediatamente assistência odontológica.
Em relação às técnicas de clareamento para dentes tratados endodonticamente, primeiramente foi realizada a mediata, também referenciada como intracoronária, com pasta clareadora obtida da mistura do peróxido de hidrogênio a $20 \%+$ perborato de sódio. Embora o pH do peróxido de hidrogênio na fase líquida seja ácido, quando misturado ao perborato de sódio, resulta numa pasta de $\mathrm{pH}$ alcalino, ${ }^{19}$ o que pode contribuir para minimizar os danos no tecido dentinário. $\mathrm{O}$ perborato de sódio também pode ser misturado com água destilada, mas, por gerar menor número de radicais hidroxilas, apresenta menor longevidade de ação, sendo necessárias mais sessões clínicas de troca da pasta clareadora. ${ }^{20}$

Na sequência, foi realizado o clareamento pela técnica imediata com peróxido de hidrogênio a $35 \%$ aplicado na face palatina, intracoronária, e na face vestibular, extracoronária, sob isolamento absoluto como forma de conveniência para proteção do tecido gengival. Embora a utilização de peróxido de hidrogênio mais concentrado possa resultar em maior quantidade de oxigênio nascente e, consequentemente, ação mais rápida, isso não significa ser mais efetivo. ${ }^{4,21}$

Considerando que o grau de difusão, a efetividade e a longevidade do clareamento mantêm relação com o tempo de contato do agente clareador com os substratos dentários, ${ }^{22}$ optou-se pela a associação de técnicas, ou seja: $1^{0}$ ) a inserção e selamento intracoronário da pasta clareadora por sete dias, a cada sessão, na técnica mediata; e $2^{\circ}$ ) a aplicação intra e extracoronária do peróxido de hidrogênio a 35\% por 45 minutos, a cada sessão. Após cada sessão de clareamento pela técnica imediata, pasta de hidróxido de cálcio foi selada no interior da câmara pulpar com o propósito de neutralizar ou alcalinizar o $\mathrm{pH}$ da região cervical e, assim, minimizar os efeitos do pH do agente clareador como um provável causador da reabsorção radicular externa. ${ }^{23,24}$ 
Apesar do clareamento em dentes tratados endodonticamente ser comprovadamente efetivo, seu sucesso não é previsível.7 No presente trabalho, a aplicação de agentes clareadores em diferentes concentrações, tempos de ação e técnicas não foi suficiente para reverter a alteração cromática do dente 21 de forma conservadora. Assim, optouse pelo desgaste conservador da face vestibular e restauração com resina composta de forma direta, pois o desgaste dentário nesse procedimento é menos profundo e, portanto, mais conservador. ${ }^{25}$ Além disso, pode ser feita em apenas uma sessão, possui baixo custo ao paciente e, a partir da evolução das resinas compostas, é possível restaurar a estética dos dentes anteriores com naturalidade. ${ }^{25}$

\section{CONCLUSÃO}

Com base no tratamento relatado e na proservação de 24 meses, podemos concluir que:

1. O clareamento dentário, nas suas diversas modalidades (técnicas) e produtos, embora conservador às estruturas dentárias, nem sempre é efetivo na resolução de problemas de alterações cromáticas.

2. O preparo da face vestibular, para posterior restauração direta com resina composta, embora menos conservador, foi uma proposta adequada à resolução do problema estético relatado pela paciente, a partir da limitação das técnicas e agentes clareadores utilizados.

\section{REFERÊNCIAS}

1. Joiner A. Tooth colour: a review of the literature. J Dent. 2004;32(Suppl 1):3-12. doi: 10.1016/j.jdent.2003.10.013.

2. Joiner A. The bleaching of teeth: a review of the literature. J Dent. 2006;34(7):412-9. doi: 10.1016/j.jdent.2006.02.002.

3. Shackelford RE, Kaufmann WK, Paules RS. Oxidative stress and cell cycle checkpoint function. Free Radic Biol Med. 2000;28(9):1387-404. doi: 10.1016/So891-5849(oo)00224-0.

4. Tredwin CJ, Naik S, Lewis NJ, Scully C. Hydrogen peroxide tooth-whitening (bleaching) products: review of adverse effects and safety issues. Br Dent J. 2006;200(7):371-6. doi: 10.1038/ sj.bdj.4813423.
5. Arikan V, Sari S, Sonmez H. Bleaching a devital primary tooth using sodium perborate with walking bleach technique: a case report. Oral Surg Oral Med Oral Pathol Oral Radiol Endod. 2009;107(5):e80-4. doi: 10.1016/j.tripleo.2009.01.050.

6. Kasuya AVB, Favarão IN, Souza JL, Cardoso SA, Fonseca RB, Hoeppner MG. Longevidade de clareamento em dente não vital com associação de técnicas: relato de caso. Rev Dental Press Estet. 2012;9(2):104-13.

7. Baratieri LN, Monteiro S Jr, Andrada MAC. Clareamento dental. São Paulo: Livraria Santos; 1993.

8. Bezerra-Júnior DM, Silva LM, Martins Lde M, Cohen-Carneiro F, Pontes DG. Esthetic rehabilitation with tooth bleaching, enamel microabrasion, and direct adhesive restorations. Gen Dent. 2016;64(2):60-4.

9. Friedman S, Rotstein I, Libfeld H, Stabholz A, Heling I. Incidence of external root resorption and esthetic results in 58 bleached pulpless teeth. Endod Dent Traumatol. 1988;4(1):23-6. doi: 10.1111/j.1600-9657.1988.tboo288.x.

10. Rotstein I, Zyskind D, Lewinstein I, Bamberger N. Effect of different protective base materials on hydrogen peroxide leakage during intracoronal bleaching in vitro. J Endod. 1992;18(3):114-7. doi: 10.1016/Soo99-2399(06)81310-5.

11. Deveaux E, Hildelbert P, Neut C, Boniface B, Romond C. Bacterial microleakage of Cavit, IRM and TERM. Oral Surg Oral Med Oral Pathol 1992;74(5):634-43.

12. Grillo JPF, Uzeda M, Alves FRF, Gonçalves LS. Seladores coronários temporários: determinação da atividade antimicrobiana in vitro. Rev Assoc Paul Cir Dent. 2013;67(2):136-40.

13. Heller D, Skriber J, Lin LM. Effect of intracoronal bleaching on external cervical root resorption. J Endod. 1992;18(4):145-8. doi: 10.1016/Soo99-2399(06)81407-X.

14. Madison S, Walton R. Cervical root resorption following bleaching of endodontically treated teeth. J Endod. 1990;16(12):570-4. doi: 10.1016/So099-2399(07)80199-3.

15. Rotstein I, Friedman S. pH variation among materials used for intracoronal bleaching. J Endod. 1991;17(8):376-9. doi: 10.1016/ Soo99-2399(06)81988-6.

16. Cvek M, Lindvall AM. External root resorption following bleaching of pulpless teeth with oxygen peroxide. Endod Dent Traumatol. 1985;1(2):56-6o. doi: 10.1111/j.1600-9657.1985.tboo561.x.

17. Lado EA, Stanley HR, Weisman MI. Cervical resorption in bleached teeth. Oral Surg Oral Med Oral Pathol. 1983;55(1):78-80.

18. Zimmerli B, Jeger F, Lussi A. Bleaching of nonvital teeth: a clinically relevant literature review. Schweiz Monatsschr Zahnmed. 2010;120(4):306-20. 
19. Besegato JF, Rocha GSR, Amorim MS, Salomão FM, Poletto D, Aida KL, et al. Aferição do pH de diferentes agentes clareadores indicados para o clareamento intracoronário. Clin Lab Res Den. 2018:1-5. doi: 10.11606/issn.2357-8041.clrd.2018.143185.

20. Weiger R, Kuhn A, Löst C. In vitro comparison of various types of sodium perborate used for intracoronal bleaching of discolored teeth. J Endod. 1994;20(7):338-41.

21. Dietschi D, Rossier S, Krejci I. In vitro colorimetric evaluation of the efficacy of various bleaching methods and products. Quintessence Int. 2006;37(7):515-26. doi: 10.1016/Soo992399(06)80096-8.
22. Riehl H. Considerações clínicas sobre terapia de clareamento dental. Scientifica. 2007;1(1):68-78.

23. Demarco FF, Freitas JM, Siva MP, Justino LM. Microleakage in endodontically treated teeth; influence of calcium hydroxide dressing following bleaching. Int Endod J. 2001;34(7):495-500. doi: 10.1046/j.1365-2591.2001.00418.x.

24. Glockner K, Hulla H, Ebeleseder K, Städtler P. Five-year follow-up of internal bleaching. Braz Dent J. 1999;10(2):105-10.

25. Hirata R, Mazzetto AH, Yao E. Alternativas clínicas de sistemas de resinas compostas laboratoriais: quando e como usar. J Bras Clin Estet Odontol. 2000;4(19):13-21. 